\title{
Spinocerebellar ataxia type 10
}

INSERM

\section{Source}

INSERM. (1999). Orphanet: an online rare disease and orphan drug data base.

Spinocerebellar ataxia type 10. ORPHA:98761

Spinocerebellar ataxia type 10 (SCA10) is a subtype of type I autosomal dominant cerebellar ataxia (ADCA type I; see this term). It is characterized by slowly progressive cerebellar syndrome and epilepsy, sometimes mild pyramidal signs, peripheral neuropathy and neuropsychological disturbances. 